\title{
A Proposed Model-Based Methodology for Feature-Specific Prediction for High-Impact Weather
}

\author{
Jacob R. Carley, Benjamin R. J. Schwedler, Michael E. Baldwin, And Robert J. Trapp \\ Department of Earth and Atmospheric Sciences, Purdue University, West Lafayette, Indiana
}

JOHN KWIATKOWSKI

NWS, Indianapolis, Indiana

JEFFREY LOGSDON

NWS, North Webster, Indiana

STEVEn J. Weiss

NOAA/NWS/Storm Prediction Center, Norman, Oklahoma

(Manuscript received 3 August 2010, in final form 5 October 2010)

\begin{abstract}
A feature-specific forecasting method for high-impact weather events that takes advantage of high-resolution numerical weather prediction models and spatial forecast verification methodology is proposed. An application of this method to the prediction of a severe convective storm event is given.
\end{abstract}

\section{Introduction}

Timely and accurate delivery of weather information is an integral part of the forecasting process; however, forecasters continue to be presented with an everincreasing volume of data. While convection-permitting numerical weather prediction models (i.e., nonhydrostatic models with horizontal grid spacing less than $\sim 4 \mathrm{~km}$ ) can provide valuable forecast information for high-impact weather events by producing realistic mesoscale spatial structures useful in identifying convective modes (Kain et al. 2008; Schwartz et al. 2009), they also contribute substantially to the volume of data that the forecaster needs to interpret. By identifying model-predicted mesoscale and near-storm-scale features of potential forecast interest, the methodology proposed herein offers guidance on the most relevant model-output products to consider, thus enhancing forecaster efficiency. This feature-specific approach is conceptually analogous to very short-term prediction with real-time radar data,

Corresponding author address: Jacob R. Carley, Purdue University, 550 Stadium Mall Dr., West Lafayette, IN 47907.

E-mail: jrcarley@purdue.edu where each storm (feature) has specific, defining attributes. Accordingly, we define features as entities of potential forecaster interest that are characterized by specific attributes in model fields.

The forecast verification community has already begun to recognize this fundamental change in how forecasts are made through collaborative efforts such as the Spatial Forecast Verification Methods Intercomparison Project (ICP; information online at http://www.ral.ucar. edu/projects/icp/). The prediction community, while continuing to produce convection-permitting forecasts, has not yet fully harnessed this capability. Until now, featurespecific prediction has been applied to a limited number of areas such as tropical cyclone track forecasting (e.g., Bender et al. 1993; Goerss 2000), midlatitude cyclone tracking (e.g., Hodges 1994; Hodges et al. 2003), severe weather composite chart analysis (Miller 1972), and nowcasting techniques that have primarily relied on observed data to produce short-term forecasts of convective systems (e.g., Dixon and Wiener 1993; Han et al. 2009; Johnson et al. 1998; Pierce et al. 2000).

Nowcasting techniques typically rely on the time extrapolation of observations and are limited in the extent to which they can describe existing features. 
Convection-permitting numerical model forecasts, however, are in wide use in the forecasting community and contain a more detailed description of the atmosphere. The attributes associated with mesoscale circulations from convection-permitting numerical weather prediction have been used to develop "surrogate" severe weather reports for forecasting as well as climate-related purposes (e.g., Sobash et al. 2009; Trapp et al. 2007; Trapp et al. 2010). Additionally, Kain et al. (2010) have proposed a novel approach to high-impact weather prediction based upon the identification of hourly maximum fields. These efforts have facilitated the classification of selected model-predicted convective attributes to supplement the traditional approach of evaluating the model-predicted convective environment. Furthermore, forthcoming advances in data assimilation, modeling, and ensemble prediction hopefully will improve the shortterm prediction of mesoscale and storm-scale phenomena (Stensrud et al. 2009).

Identification of model-generated features, or entities, of forecaster interest constitutes the foundation of what shall be known as feature-specific prediction (FSP). This approach to forecasting would ideally retain the useful information pertaining to the mesoscale environment and relevant forcing mechanisms for ascent while providing insights into storm type (e.g., supercell thunderstorms) and intensity by identifying significant features within a forecast field. FSP is not, however, limited to convective systems and can be applied to any identifiable meteorological feature. This methodology would also seek to enhance the ingredients-based forecasting approach (e.g., Johns and Doswell (1992) and Doswell et al. (1996)) by providing forecasters quick insights into what may be an impending high-impact weather threat. Faster identification of a potential event allows forecasters more time to evaluate the environmental ingredients associated with that event.

This paper proposes a FSP methodology that stems from the forecast verification community. This community has developed many diverse feature identification methods for use with high-resolution numerical weather prediction. Since these new spatial verification techniques are used in the verification of forecasts, it is logical to also test and apply them as a prediction tool. Examples of techniques include agglomerative cluster analysis methods (Lakshmanan et al. 2003; Peak and Tag 1994), identifying areas of contiguous rainfall enclosed within a specified isohyet (Ebert and McBride 2000), procedures involving thresholding fields smoothed through a convolution process (Davis et al. 2006), a multiscale iterative cluster analysis technique (Marzban and Sandgathe 2006, 2008), and a method of identifying objects as clusters of pixels exceeding a size and intensity threshold (Micheas et al. 2007). Finally, Baldwin et al. (2005) have developed an automated procedure to classify rainfall systems via threshold, size, and proximity. In this paper we shall make use of the Baldwin et al. (2005) algorithm, hereafter known as the Baldwin Object Oriented Identification Algorithm (BOOIA), as recently applied in Hitchens et al. (2010).

Within this framework, features of potential interest are identified in forecast fields and then presented as guidance. Following Stensrud et al. (2009), FSP is intended to be a tool to facilitate further development and implementation of the warn-on-forecast framework.

\section{Methodology}

A feature-specific approach for high-impact weather forecasting begins by defining an assortment of feature types of potential interest. Upon reviewing the highimpact features in the beginning of the forecast process, the forecaster may then continue to refine the forecast by evaluating the ingredients necessary to support such high-impact feature types. For example and simplicity, we shall focus on the development and use of a single feature type: convective storms possessing significant updraft rotation. Upon receiving the numerical model output, the second step involves feature identification and tracking. As mentioned in the previous section, the BOOIA is used to identify features.

To track objects, an extension of the method described in Gilleland et al. (2008) is utilized, which uses Baddeley's $\Delta$ image metric (Baddeley 1992a,b) to determine the similarity between features identified from meteorological fields. The Baddeley metric takes into account the size, shape, and distance between features in order to solve the correspondence, or data association, problem. Instead of comparing forecasts to observations, as is done by Gilleland et al. (2008), the current method compares objects identified at consecutive times of a numerical forecast in order to determine the path and evolution of the feature(s) of interest.

Once all features have been identified and tracked over the forecast period of interest, the data must be presented to the forecaster in an easily understandable yet comprehensive format. Features can evolve rapidly with time; thus, it is desirable to have model forecast output on time scales of feature-specific evolution. For convective storm features, output corresponding to convective time scales on the order of $10 \mathrm{~min}$ would be optimal. Ideally, the FSP system would be run prior to dissemination since the distribution of raw model data to forecasters at a high temporal frequency would exhibit a potentially prohibitive bandwidth challenge. A concise decision-support system is an important component with 
TABLE 1. Physics options used in the WRF-ARW model forecast.

\begin{tabular}{lc}
\hline \hline $\begin{array}{l}\text { Yonsei University planetary } \\
\text { boundary layer (YSU) } \\
\text { Purdue Lin microphysics }\end{array}$ & Hong et al. (2006) \\
& $\begin{array}{c}\text { Lin et al. (1983); Chen } \\
\text { and Sun (2002) } \\
\text { Rapid Radiative Transfer Model } \\
\text { (RRTM) longwave radiation }\end{array}$ \\
$\begin{array}{l}\text { Dudhia shortwave radiation } \\
\text { Noah land surface model }\end{array}$ & Dudhia (1989) \\
& Ek et al. (2003)
\end{tabular}

this prediction method; it must convey a necessary amount of information to the end user while avoiding "data overload."

FSP can be summarized by three simple, qualitative steps:

1) determination of the feature type of interest,

2) feature identification and tracking, and

3) presentation to forecaster for evaluation.

\section{Application}

For this application example, version 3 of the Weather Research and Forecasting (WRF) Model's Advanced Research WRF (ARW) core (Skamarock and Klemp 2008) is used to generate high spatial $(\Delta x=\Delta y=4.25 \mathrm{~km})$ and temporal (10-min output frequency) resolution forecasts for a case of deep convective storms over Oklahoma on 5-6 November 2008. The model was initialized at 0000 UTC 5 November and integrated forward $36 \mathrm{~h}$ in time over a domain covering two-thirds of the contiguous United States. The operational 12-km North American Mesoscale Model (NAM; Rogers et al. 2009) was used for initial and lateral boundary conditions. Table 1 shows the physics configuration for this model simulation. This example focuses on the 0100-0300 UTC period valid 6 November, during which time one tornado and many occurrences of severe wind and large hail were reported in Oklahoma (Fig. 1).

\section{a. Feature identification}

Convective features with supercellular characteristics are of primary interest on this day, owing to the tendency for supercells to be associated with multiple types of severe weather (e.g., Moller et al. 1994; Bunkers et al. 2006; Thompson et al. 2008; Duda and Gallus 2010). The basic convective features composed of continuous regions of model-simulated composite radar reflectivity factor (Koch et al. 2005) were identified using the BOOIA. Following Parker and Johnson (2000), a simulated reflectivity threshold of $\geq 40 \mathrm{dBZ}$ was used to identify model-generated convective features (Figs. 1 and 2). No minimum size limit was imposed on the

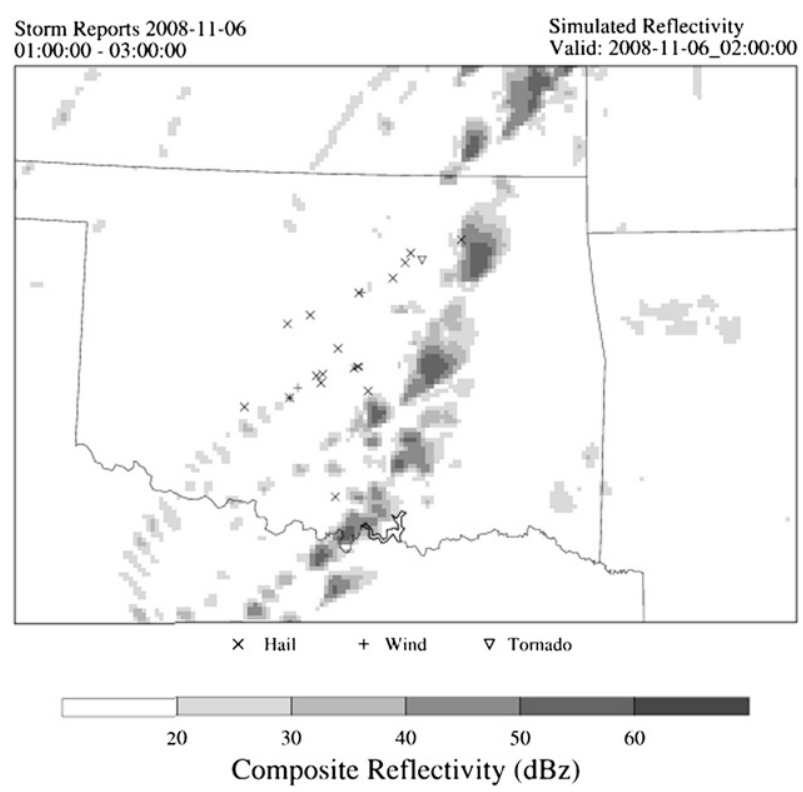

FIG. 1. Storm reports spanning the 0100-0300 UTC inclusive time period on 6 Nov 2008 and the simulated composite radar reflectivity factor from a 26-h WRF forecast valid 0200 UTC 6 Nov 2008. The storm reports were taken from the Storm Prediction Center's Severe Weather Database (SPC 2010).

40-dBZ feature identification; however, features were restricted to a $2 \times \Delta x$ search radius. This search radius implies that grid points meeting the radar reflectivity factor threshold and within a $2 \times \Delta x$ distance are combined into one distinct object. Each convective feature was then constrained a last time according to midlevel updraft helicity (UH), which is defined following Kain et al. (2008) as

$$
\mathrm{UH}=\int_{z=2 \mathrm{~km}}^{z=5 \mathrm{~km}} w \zeta d z
$$

where $w$ is the vertical velocity, $\zeta$ is the vertical vorticity, and $z$ is the height above ground level. Since this quantity is a measure of the correlation between midlevel vertical velocity and vertical vorticity, it can be used to identify model-generated mesocyclones. Therefore, mesocyclonic features are defined as convective features containing a maximum-within-feature value of UH exceeding a threshold. Based on analysis by Trapp et al. (2010) and for the sake of example, three separate UH thresholds were used to identify weakly $\left(30 \mathrm{~m}^{2} \mathrm{~s}^{-2}\right)$, moderately $\left(50 \mathrm{~m}^{2} \mathrm{~s}^{-2}\right)$, and strongly $\left(70 \mathrm{~m}^{2} \mathrm{~s}^{-2}\right)$ mesocyclonic features (Fig. 2). For future applications of FSP, more exploratory studies should be conducted in order to select optimal thresholds.

The convective feature field (Fig. 2) identifies which areas within the reflectivity field (Fig. 1) meet the minimum 


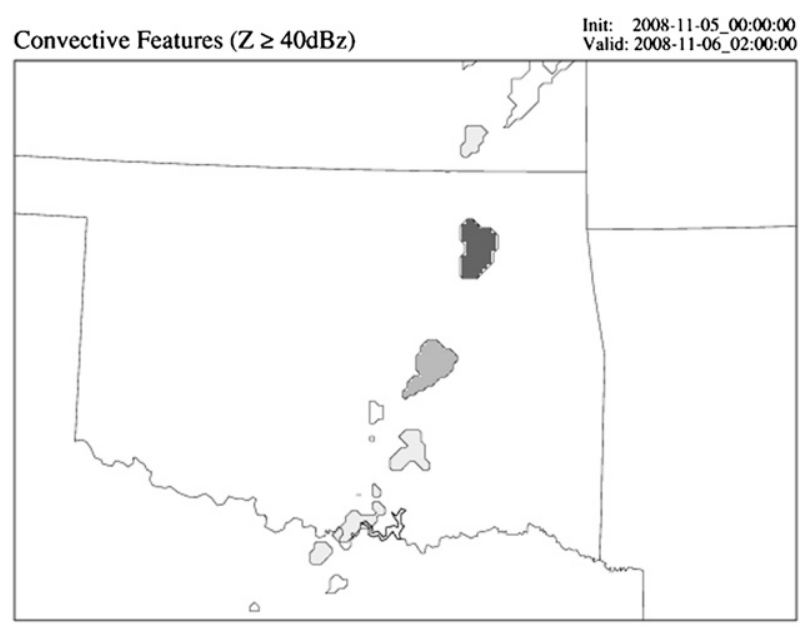

$\mathrm{UH} \geq 30 \mathrm{~m}^{2} / \mathrm{s}^{2}$

$\mathrm{UH} \geq 50 \mathrm{~m}^{2} / \mathrm{s}^{2}$

FIG. 2. Convective features derived from simulated composite reflectivity $\geq 40 \mathrm{dBZ}$ valid 0200 UTC 6 Nov 2008 are outlined. Weakly mesocyclonic convective features $\left(\mathrm{UH} \geq 30 \mathrm{~m}^{2} \mathrm{~s}^{-2}\right.$ ), moderately mesocyclonic convective features ( $\mathrm{UH} \geq 50 \mathrm{~m}^{2} \mathrm{~s}^{-2}$ ), and strongly mesocyclonic convective features $\left(\mathrm{UH} \geq 70 \mathrm{~m}^{2} \mathrm{~s}^{-2}\right.$ ) are shown using shading.

criteria for feature identification. The shading in Fig. 2 further emphasizes the potentially significant features according to the three UH thresholds discussed previously. Upon comparing Figs. 1 and 2, it is apparent how the feature-specific identification is able to benefit the forecasting process by immediately calling forecasters' attention to the strongly mesocyclonic feature amidst a region of high simulated reflectivity.

\section{b. Feature tracking}

Additional information can be provided by the automated tracking of mesocyclonic features through time. For example, it is possible to determine more about the temporal morphological characteristics of the modelpredicted phenomena by processing and displaying information about the path and duration of these features. This information can be used to determine, such as in this example, if the environment is supportive of longtrack supercell thunderstorms. Figure 3 shows the time evolution of moderately mesocyclonic features identified in the model forecast for the period from 0100 to 0300 UTC 6 November. Three distinct paths are evident: two of which persist for $2 \mathrm{~h}$ and one that is continuous for nearly $1 \mathrm{~h}$. In particular, the northernmost predicted track appears to remain a single cell and could be indicative of a long-track supercell. This type of information can be very beneficial to forecasters since it immediately shows the storm type (convective-mesocyclonic), temporal duration, relative organization, direction of movement, and
Forecast Tracks: Moderately Mesocyclonic Features $\begin{aligned} & \text { Begin: 2008-11-06_01:00:00 } \\ & \text { End: 2008-11-06_03:00:00 }\end{aligned}$

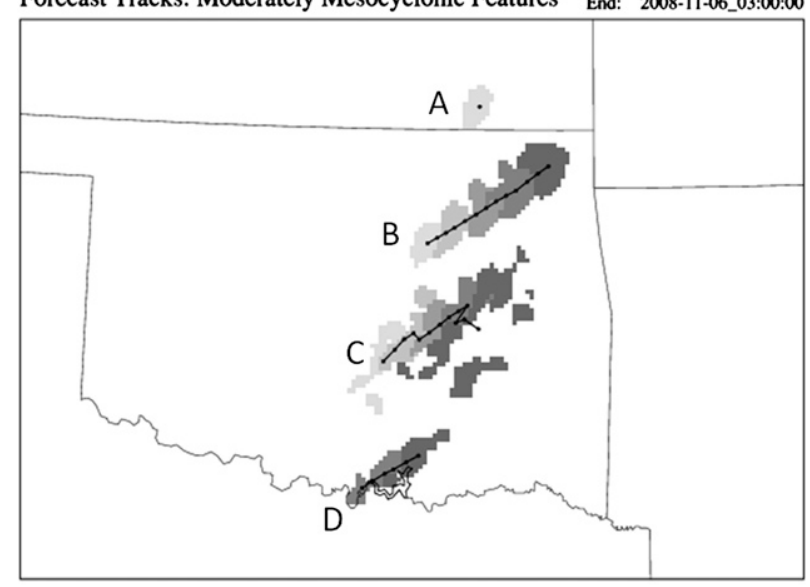

\begin{tabular}{l|l|l|l|l|l|} 
Time (UTC) & $01: 00$ & $01: 30$ & $02: 00$ & $02: 30$ & $03: 00$
\end{tabular}

\begin{tabular}{|c|c|c|c|c|}
\hline $\begin{array}{c}\text { Feature } \\
\text { ID }\end{array}$ & $\begin{array}{c}\text { Start Time } \\
\text { (UTC) }\end{array}$ & $\begin{array}{c}\text { End Time } \\
\text { (UTC) }\end{array}$ & $\begin{array}{c}\text { Temporal } \\
\text { Persistence } \\
\text { (minutes) }\end{array}$ & $\begin{array}{c}\text { Max dBZ } \\
\text { (time UTC) }\end{array}$ \\
\hline A & $01: 00: 00$ & $01: 00: 00$ & $<10$ & $54.00(0100)$ \\
\hline B & $01: 00: 00$ & $03: 00: 00$ & 120 & $58.88(0140)$ \\
\hline C & $01: 00: 00$ & $03: 00: 00$ & 120 & $58.81(0140)$ \\
\hline D & $02: 10: 00$ & $03: 00: 00$ & 50 & $56.92(0210)$ \\
\hline
\end{tabular}

FIG. 3. Moderately mesocyclonic feature tracks $\left(\mathrm{UH} \geq 50 \mathrm{~m}^{2} \mathrm{~s}^{-2}\right)$ spanning the 0100-0300 UTC time period on 6 Nov 2008. Dots indicate the location of the centroid of the feature at 10 -min intervals. Shading indicates the location of features at 30-min intervals. This figure, in conjunction with the attached table, also serves to represent a hypothetical decision support system. The attributes table provides information about each feature over the period of interest including the feature ID, feature track startend times, feature lifespan (temporal persistence), and maximum simulated composite reflectivity with the time of occurrence. The temporal persistence column contains text emphasis associated with features that express temporal persistence $>30 \mathrm{~min}$. Italics represent persistence $>30 \mathrm{~min}$, boldface $>60 \mathrm{~min}$, and boldface italics $>90 \mathrm{~min}$.

affected region all in one image. A comparison of the mesocyclonic features (Fig. 2), the tracks (Fig. 3), and the storm reports (Fig. 1) demonstrate that FSP would have been a useful tool for identifying this region in Oklahoma for an impending severe weather threat. It must also be noted that this is an example of a particularly good model forecast, and while the FSP appears to perform particularly well within this context, it may not appear so if the model forecast is poor.

\section{c. Decision support system}

A decision support system is recommended to convey the quantitative measures of each feature (e.g., the 
Warning Decision Support System-Integrated Information; Lakshmanan et al. 2007). Figure 3 also serves to demonstrate one such method of communicating feature attributes from a single model run. This decision support system presents feature tracks and includes a feature attribute table that provides information about each feature. As is done similarly in very short-term predictions with real-time radar data, specific attributes worthy of forecaster attention can be emphasized within the attributes table, such as temporal persistence (i.e., features B, C, and D in Fig. 3).

Ensemble-based probabilistic information concerning features and feature attributes may also be conveyed with an extension of the FSP method. Within this context a decision support system could provide probabilistic information regarding feature track and attribute variability. If tracks from multiple ensemble members have similar feature attributes and locations, the forecaster, in principle, can be more confident in the type of event that may occur. This method would be ideally suited for short-range, storm-scale ensemble forecasts.

\section{Discussion}

The FSP procedure is a potentially straightforward and useful method with its origins in the object-oriented forecast verification community. The FSP method demonstrates promise for improving the high-impact weather forecasting process by focusing on the automated identification of important model-generated forecast information such as feature type, temporal duration, organization, and movement. Compared to the approach presented by Kain et al. (2010), which identifies model-produced hourly maximum exceedance fields, the FSP approach is distinguished by the direct determination of specific features and their respective attributes. These characteristics make the FSP procedure a potentially useful approach for application within a warn-on-forecast framework.

The demonstration presented here focused on a severe convective weather event; however, the FSP approach could be applied to other weather scenarios such as lake-effect snowfall or heavy rain. For a heavy-rain event, FSP would be tuned to identify a feature that possesses temporal continuity over a specified time frame, little spatial variability, and a rain rate exceeding a predetermined threshold. This would allow for features to be classified by "heavy rain potential" according to their predicted rain rate as well as their predicted spatial and temporal persistence levels.

The application of FSP methods to a variety of highimpact weather phenomena may aid in the identification of multiple weather threats. While initial knowledge of the primary feature threat may be known, knowledge of a secondary feature type may not be immediately apparent. Therefore, a linking of various features of interest could be used to identify risks associated with the evolving weather scenario. For example, the feature of interest may begin as a set of mesocyclonic features but subsequently may evolve toward flash flooding by the close of the forecast period. This type of decision support system could be implemented as a part of the suite of model-derived products that are disseminated to operational forecasters.

This approach to forecasting facilitates a rapid characterization of a high-impact weather threat and can help forecasters use their decision-making time more effectively. If the FSP methodology is combined with ensemble prediction and a decision support system, uncertainty and quantitative feature attributes can also be evaluated in an expedient manner. When potential threats are identified immediately, a more thorough analysis of the ingredients necessary to support the event can be conducted to evaluate the likelihood of the event's occurrence.

Acknowledgments. This research was a part of a COMET/UCAR Cooperative Project (UCAR Sub-Award S07-66813). Jacob Carley and Benjamin Schwedler were also supported under a National Science Foundation graduate research fellowship. Computing resources for WRF model simulations were provided by Purdue University's Rosen Center for Advanced Computing. Comments from two anonymous reviewers helped improve this manuscript. The authors would also like to extend thanks to Eric Gilleland for discussions regarding the Baddeley metric.

\section{REFERENCES}

Baddeley, A. J., 1992a: An error metric for binary images. Robust Computer Vision: Quality of Vision Algorithms, W. Förstner and S. Ruwiedel, Eds., Wichmann, 59-78.

- 1992b: Errors in binary images and an $\mathrm{L}^{\mathrm{p}}$ version of the Hausdorff metric. Nieuw Arch. Wiskunde, 10, 157-183.

Baldwin, M. E., J. S. Kain, and S. Lakshmivarahan, 2005: Development of an automated classification procedure for rainfall systems. Mon. Wea. Rev., 133, 844-862.

Bender, M. A., R. J. Ross, R. E. Tuleya, and Y. Kurihara, 1993: Improvements in tropical cyclone track and intensity forecasts using the GFDL initialization scheme. Mon. Wea. Rev., 121, 2046-2061.

Bunkers, M. J., M. R. Hjelmfelt, and P. L. Smith, 2006: An observational examination of long-lived supercells. Part I: Characteristics, evolution, and demise. Wea. Forecasting, 21, 673-688.

Chen, S.-H., and W.-Y. Sun, 2002: A one-dimensional time dependent cloud model. J. Meteor. Soc. Japan, 80, 99-118.

Davis, C. A., B. G. Brown, and R. G. Bullock, 2006: Object-based verification of precipitation forecasts. Part I: Methodology and 
application to mesoscale rain areas. Mon. Wea. Rev., 134, $1772-1784$.

Dixon, M., and G. Wiener, 1993: TITAN: Thunderstorm Identification, Tracking, Analysis, and Nowcasting-A radar-based methodology. J. Atmos. Oceanic Technol., 10, 785-797.

Doswell, C. A., III, H. E. Brooks, and R. A. Maddox, 1996: Flash flood forecasting: An ingredients-based methodology. Wea. Forecasting, 11, 560-581.

Duda, J. D., and W. A. Gallus Jr., 2010: Spring and summer midwestern severe weather reports in supercells compared to other morphologies. Wea. Forecasting, 25, 190-206.

Dudhia, J., 1989: Numerical study of convection observed during the Winter Monsoon Experiment using a mesoscale twodimensional model. J. Atmos. Sci., 46, 3077-3107.

Ebert, E. E., and J. L. McBride, 2000: Verification of precipitation in weather systems: Determination of systematic errors. J. Hydrol., 239, 179-202.

Ek, M. B., K. E. Mitchell, Y. Lin, E. Rogers, P. Grunmann, V. Koren, G. Gayno, and J. D. Tarpley, 2003: Implementation of Noah land surface model advances in the National Centers for Environmental Prediction operational mesoscale Eta Model. J. Geophys. Res., 108, 8851, doi:10.1029/2002JD003296.

Gilleland, E., T. C. M. Lee, J. Halley Gotway, R. G. Bullock, and B. G. Brown, 2008: Computationally efficient spatial forecast verification using Baddeley's delta image metric. Mon. Wea. Rev., 136, 1747-1757.

Goerss, J. S., 2000: Tropical cyclone track forecasts using an ensemble of dynamical models. Mon. Wea. Rev., 128,1187-1193.

Han, L., S. Fu, L. Zhao, Y. Zheng, H. Wang, and Y. Lin, 2009: 3D convective storm identification, tracking, and forecasting-An enhanced TITAN algorithm. J. Atmos. Oceanic Technol., 26, 719-732.

Hitchens, N. M., R. J. Trapp, M. E. Baldwin, and A. Gluhovsky, 2010: Characterizing subdiurnal extreme precipitation in the midwestern United States. J. Hydrometeor., 11, 211-218.

Hodges, K. I., 1994: A general method for tracking analysis and its application to meteorological data. Mon. Wea. Rev., 122, 2573-2586.

— B. J. Hoskins, J. Boyle, and C. Thorncroft, 2003: A comparison of recent reanalysis datasets using objective feature tracking: Storm tracks and tropical easterly waves. Mon. Wea. Rev., 131, 2012-2037.

Hong, S.-Y., Y. Noh, and J. Dudhia, 2006: A new vertical diffusion package with an explicit treatment of entrainment processes. Mon. Wea. Rev., 134, 2318-2341.

Johns, R. H., and C. A. Doswell III, 1992: Severe local storms forecasting. Wea. Forecasting, 7, 588-612.

Johnson, J. T., P. L. MacKeen, A. Witt, E. D. Mitchell, G. J. Stumpf, M. D. Eilts, and K. W. Thomas, 1998: The Storm Cell Identification and Tracking algorithm: An enhanced WSR-88D algorithm. Wea. Forecasting, 13, 263-276.

Kain, J. S., and Coauthors, 2008: Some practical considerations regarding horizontal resolution in the first generation of operational convection-allowing NWP. Wea. Forecasting, 23, 931-952.

—, S. R. Dembek, S. J. Weiss, J. L. Case, J. J. Levit, and R. A. Sobash, 2010: Extracting unique information from high resolution forecast models: Monitoring selected fields and phenomena every time step. Wea. Forecasting, 25, 15361542.

Koch, S. E., B. S. Ferrier, M. T. Stoelinga, E. Szoke, S. J. Weiss, and J.S. Kain, 2005: The use of simulated radar reflectivity fields in the diagnosis of mesoscale phenomena from high-resolution WRF model forecasts. Preprints, 32nd Conf. on Radar Meteorology/ 11th Conf. on Mesoscale Processes, Albuquerque, NM, Amer. Meteor. Soc., J4J.7. [Available online at http://ams.confex.com/ ams/pdfpapers/97032.pdf.]

Lakshmanan, V., R. Rabin, and V. DeBrunner, 2003: Multiscale storm identification and forecast. J. Atmos. Res., 67, 367-380.

— Decision Support System-Integrated Information. Wea. Forecasting, 22, 596-612.

Lin, Y.-L., R. D. Farley, and H. D. Orville, 1983: Bulk parameterization of the snow field in a cloud model. J. Appl. Meteor., 22, 1065-1092.

Marzban, C., and S. Sandgathe, 2006: Cluster analysis for verification of precipitation fields. Wea. Forecasting, 21, 824-838.

- and —-, 2008: Cluster analysis for object-oriented verification of fields: A variation. Mon. Wea. Rev., 136, 10131025.

Micheas, A. C., N. I. Fox, S. A. Lack, and C. K. Wikle, 2007: Cell identification and verification of QPF ensembles using shape analysis techniques. J. Hydrol., 343, 105-116.

Miller, R. C., 1972: Notes on the analysis and severe-storm forecasting procedures of the Air Force Global Weather Central. Air Weather Service Tech. Rep. 200 (Rev.), Air Weather Service, Scott Air Force Base, IL, 190 pp.

Mlawer, E. J., S. J. Taubman, P. D. Brown, M. J. Iacono, and S. A. Clough, 1997: Radiative transfer for inhomogeneous atmospheres: RRTM, a validated correlated-k model for the longwave. J. Geophys. Res., 102 (D14), 16 663-16 682.

Moller, A. R., C. A. Doswell, M. P. Foster, and G. R. Woodall, 1994: The operational recognition of supercell thunderstorm environments and storm structures. Wea. Forecasting, 9, 327-347.

Parker, M. D., and R. H. Johnson, 2000: Organizational modes of midlatitude mesoscale convective systems. Mon. Wea. Rev., 128, 3413-3436.

Peak, J. E., and P. M. Tag, 1994: Segmentation of satellite imagery using hierarchical thresholding and neural networks. J. Appl. Meteor., 33, 605-616.

Pierce, C. E., P. J. Hardaker, C. G. Collier, and C. M. Hagget, 2000: GANDOLF: A system for generating automated nowcasts of convective precipitation. Meteor. Appl., 7, 341-360.

Rogers, E., and Coauthors, 2009: The NCEP North American Mesoscale Modeling System: Recent changes and future plans. Preprints, 23rd Conf. on Weather Analysis and Forecasting/19th Conf. on Numerical Weather Prediction, Omaha, NE, Amer. Meteor. Soc., 2A.4. [Available online at http://ams.confex. com/ams/pdfpapers/154114.pdf.]

Schwartz, C. S., and Coauthors, 2009: Next-day convection-allowing WRF model guidance: A second look at $2-\mathrm{km}$ versus $4-\mathrm{km}$ grid spacing. Mon. Wea. Rev., 137, 3351-3372.

Skamarock, W. C., and J. B. Klemp, 2008: A time-split nonhydrostatic atmospheric model for Weather Research and Forecasting applications. J. Comput. Phys., 227, 3465-3485.

Sobash, R., J. S. Kain, D. R. Bright, A. R. Dean, M. C. Coniglio, S. J. Weiss, and J. J. Levit, 2009: Forecast guidance for severe thunderstorms based on identification of extreme phenomena in convection-allowing model forecasts. Preprints, $23 \mathrm{rd} \mathrm{Conf.}$ on Weather Analysis and Forecasting/19th Conf. on Numerical Weather Prediction, Omaha, NE, Amer. Meteor. Soc., 4B.6. [Available online at http://ams.confex.com/ams/pdfpapers/ 154328.pdf.]

SPC, cited 2010: Severe weather database files. [Available online at http://www.spc.ncep.noaa.gov/wcm/\#data.] 
Stensrud, D. J., and Coauthors, 2009: Convective-scale warn-onforecast system: A vision for 2020. Bull. Amer. Meteor. Soc., 90, 1487-1499.

Thompson, R. L., J. S. Grams, and J. A. Prentice, 2008: Synoptic environments and convective modes associated with significant tornadoes in the contiguous United States. Preprints, 24th Conf. on Severe Local Storms, Savannah, GA, Amer. Meteor. Soc., 16A.3. [Available online at http://ams.confex.com/ams/ pdfpapers/142210.pdf.]
Trapp, R. J., B. A. Halvorson, and N. S. Diffenbaugh, 2007: Telescoping, multimodel approaches to evaluate extreme convective weather under future climates. J. Geophys. Res., 112, D20109, doi:10.1029/2006JD008345.

, E. D. Robinson, M. E. Baldwin, N. S. Diffenbaugh, and B. R. J. Schwedler, 2010: Regional climate of hazardous convective weather through high-resolution dynamical downscaling. Climate Dyn., doi:10.1007/s00382-0100826-y. 